\title{
THE MASKING OR DELAY IN THE DEVELOPMENT OF SYPHILIS AFTER PENICILLIN THERAPY FOR GONORRHEA*
}

\author{
BY \\ J. A. L. LEEMING \\ Guy's Hospital, London
}

The discovery of penicillin by Sir Alexander Fleming and its development by Sir Howard Florey was without doubt one of the greatest advances of medicine, and yet a few years' experience has shown that even this great bequest to humanity has not been an entirely unmixed blessing.

Laboratory trials soon showed that the gonococcus, the Treponema Fallidum and other organisms, were sensitive to this new drug. Clinical tests also showed that, unlike previous similar substances, a dosage tolerated by man still had a lethal effect on penicillin-sensitive organisms in the body. This finding, although a blessing in many ways, confronted venereologists with an entirely new problem in therapeutics, and the danger of suppressing or modifying the development of syphilis by using the new drug for the treatment of gonorrhoea in a dosage adequate for the latter but inadequate for the successful treatment of syphilis was immediately apparent. This problem has worried many clinicians who, while appreciating the numerous advantages of penicillin treatment for gonorrhœa, are now looking five or ten years ahead and wondering whether they will then be confronted with a sharp rise in incidence of the late complications. of syphilis, and especially of neurosyphilis.

The natural history of syphilis as a disease is of great interest, and there are certain aspects which are as yet imperfectly understood. The clinical development of the disease in its first few months in the untreated case is too well known to require description here, but there are even during this period certain phenomena that are difficult to explain.

*Thesis submitted for D.M. Oxon.

\section{Immunity in Syphilis}

Immunity in syphilis is a subject of great interest which has never been satisfactorily explained, and Chesney (1927), in his admirable monograph on the subject, surveys it thoroughly. He described how rabbits and monkeys, after experimental infection, may in some cases be found to harbour treponemata in their internal organs or lymph nodes and yet to show no clinical sign of disease and to have a negative serological test. Whether a previously uninfected body has any natural immunity to the disease is hard to say. The presence of antibodies in the body as agglutinins, precipitins, or opsonins has never been conclusively proved, and there is little evidence to suggest phagocytosis, but Bergel (1925) (quoted by Chesney) claims in experimental work on rabbits to have demonstrated active phagocytosis of treponemata by large lymphocytes or mononuclear cells. This important finding, however, has not been confirmed and was only found in certain stained preparations. That both rabbits and humans develop during an attack of syphilis a strong resistance to a second primary infection has been demonstrated beyond doubt experimentally and clinically; the exact nature of this immunity has not been determined. There appears to be no rise in circulating antibodies but rather an alteration in the tissue response to a second inoculation. Kraus and Volk (1906) (quoted by Chesney) suggested this acquired immunity might be regional, and the former considered the skin to be the chief site of this immunity. Brown and Pearce (1921), experimenting with rabbits, found that there was an inverse ratio 
between the initial response to syphilis inoculation and the subsequent course of the disease, and they formulated a "law of inverse proportion."

Chesney and Kemp (1925) showed that a second infection in the rabbit may show no local lesion-a fact which they attributed to local change-and yet may cause a bloodborne infection, this fact suggesting that other tissues have not developed this high immunity. The variations in the activity of the disease in its different stages have been explained by two hypotheses. The first, that the Treponema pallidum has a complex life cycle with varying powers of invasiveness, has now for the most part been abandoned in favour of the theory of some allergic alteration in tissue response to the treponema.

Morgan (1939), in his experimental work with rabbits, used special suspensions of treponemata in varying concentrations and was thus able to inoculate rabbits with varying strengths of inoculum: He made the significant discovery that when a minimal number of treponemata were used no local lesions were produced, and subsequent observation with serological tests and post-mortem examinations showed no signs of a syphilitic infection; employing rather larger numbers, he again found no lesions at the site of inoculation but subsequently the animals developed positive serological tests; in a third group with still larger numbers the demonstrated both the typical clinical picture of experimental syphilis and a local lesion at the site of inoculation. Subsequently he was able to show that an inoculation of less than 30,000 treponemata in a rabbit did not produce àny local lesions but did cause a generalized infection with a positive serological test. He suggested that the same results were likely to be found in naturally acquired syphilis in man. In considering this it must be remembered that the skin and mucous membranes in rabbits are not so susceptible to local lesions as those in humans. Morgan observed that statistically syphilis in the early stages of the disease was, in America, commoner in men, who out-numbered women in the proportion of about $2: 1$, while treatment of the late complications of the disease showed that women patients formed 53 per cent. of the total. He went so far as to suggest that, in his experience, half the patients who were under treatment for severe late complica- tions such as cardiovascular syphilis or neurosyphilis had had no signs or symptoms in the early stages. The healing stages of the chancre and the disseminating secondary syphilis are accompanied by massive destruction of treponemata by some agency unknown, and the disease is frequently then restricted to an inactive local form. He considered that inadequate treatment of syphilis in the early stages might interfere with this natural tendency to localize the infection into a relatively innocuous form. He claimed that such inadequate treatment raised the incidence of serious late complications in syphilis by some 10 or 15 per cent.

\section{Boeck's Experiment with Untreated Syphilis}

The greatest experiment of all time in untreated syphilis was carried out by Boeck in the years 1891 to 1916 at his Oslo clinic. He maintained that iodides and mercury, the only remedies of his day, were symptomatic remedies which not only failed to eradicate the disease but paralysed the body's natural defences, leaving certain parts, especially the central nervous system, vulnerable, to the organisms. During the stated period he saw 2,181 patients who were diagnosed clinically as suffering from syphilis and who received no treatment from him ; the possibility that some of them received treatment elsewhere cannot be entirely dismissed. In 1929 at a discussion in Oslo on these cases Bruusgaard and Dahlström, two former pupils of Boeck, gave some very interesting figures of the results of this treatment, or rather lack of it, by Boeck. At this discussion Bruusgaard disclosed that he had managed to examine 309 survivors of Boeck's original group and obtained clinical or post-mortem findings on 164 who had died since having originally been seen and diagnosed. All the living patients were given a thorough clinical examination, and had their hearts radiographed. The majority were tested serologically, and the cerebrospinal fluids of a few were examined. Of the 164 who died, the majority had died in Oslo hospitals, the cause of death being known and complete postmortem examination having been performed on 40 cases. Of this total of 473 cases thus re-examined more than twenty years after their initial untreated infection, only 37 per cent. had developed any active lesion of late syphilis, 14 per cent. showed a positive sero- 
logical reaction but no other signs of the disease, 22 per cent: had died from other causes, one half of these cases over a period of twenty years had developed no obvious lesions of syphilis, and 27 per cent. showed clinical arrest or spontaneous cure and gave a negative serological test. Approximately 14 per cent. were suffering from cardiovascular disease, 2.5 per cent. contracted general paralysis of the insane, and just over 1 per cent. were found to have tabes. As, however, all the cases of general paralysis of the insane in Oslo over this period had been carefully separated for hospital treatment, it is reasonable to suppose that this figure represents the number of such cases developing from the original 2,181 patients rather than from the 473 Bruusgaard was able to find, and therefore this figure may more accurately represent a percentage of 0.6 per cent. Dahlström pointed out at the same discussion that this last figure compared very favourably with the usual percentage after treatment, which he estimated as 4 per cent. He also stated that in his psychological clinic he had very few G.P.I. cases which had been under Boeck's treatment, but he had seen a considerable number which had received mercury or iodides. Discussing the two G.P.I. cases of Boeck's which he had seen, he suggested that they also might have been given these drugs by other doctors whom they had visited. He drew an analogy with the rarity of G.P.I. among tramps and negroes, other than those of the latter who lived in large cities where treatment for syphilis was readily available.

Stokes and his fellow workers (1934), in a survey of the accomplishment of treatment in early syphilis, compared their records after treatment with Bruusgaard's figures. In cardiovascular complications they found an appreciable improvement- in their figures as compared with Bruusgaard's. The greatest discrepancy in their two analyses is that of late skin, mucosal, and bone syphilis, where Stokes's percentage in the 3 to 10 year group was 1.2 per cent., while Bruusgaard's was 31.7 per cent. This finding is of interest in connexion with Brown and Pearce's (1921) theory of the protective influence on the rest of the body of skin and mucosal manifestations of syphilis. It must be remembered that Stokes's figures are those of adequately treated syphilis ; the untreated patients of Boeck's series whose skin manifestations were not treated sympto- matically in any way seem to have been protected surprisingly well from neurosyphilis. How much that protection would be interfered with by modifying the early manifestations of syphilis is a matter for thought; the available evidence suggests that these skin manifestations are a vital factor in natural immunity. Stokes compares some results of inadequate treatment favourably with Bruusgaard's but admits that by inadequate treatment he means cases having had less than twenty injections of arsenic in some form; he does not include a series of patients who have had one or two injections only of this drug, which would be analogous to the critical point in this paper and which might have interfered with the cutaneous manifestations of the disease without being in any way likely to destroy all the organisms present in the body.

\section{Inadequate Arsenical and Penicillin Treatment}

Statistics showing results after entirely inadequate arsenical treatment are naturally not much in evidence, but Kemp and Menninger (1936), reviewing the subject, suggested that the frequent early development of late complications of the disease could be attributed to inadequate treatment in the early stage. There are grounds for belief that the actual incidence of these late complications is also raised by such treatment. That a similar phenomenon may be found with penicillin is suggested by Cole and his fellow workers (1946). They treated a series of 31 cases of syphilis in the primary or secondary stage with 1,000 units of penicillin given threehourly for seven days, thus giving a total of. 56,000 units. They report that 13 of these cases relapsed within one year, and of these 5 are described as " neuro-relapses." A further series of 81 cases were described which were given a total of 300,000 units similarly spaced. In this series they report 26 relapses within one year, among which were 10 cases of neurosyphilis. - Unfortunately they give no further clinical details of these cases. Although no true comparison can be drawn between such protracted treatment and single large doses or treatment spread over a few hours, these results are disturbing and it must be remembered that Kemp and Menninger (1936) showed that the earlier the inadequate arsenic therapy was given the greater was the likelihood 
of the early onset of late complications of syphilis. The potential danger of penicillin treatment in a dosage insufficient to cure syphilis during the possible incubation period of this disease seems on these findings alone to be very real, and yet no such cases have been reported in the literature and I have heard of no such cases of this type. The time, however, is yet early and we cannot dismiss this possibility lightly.

It has already been pointed out that Kemp and Menninger (1936) showed that inadequate arsenical treatment, while apparently curing the obvious visible signs of syphilis in the early stages, may very considerably shorten the period of latency before symptoms and signs of later complications, especially neurosyphilis, develop ; it is also likely, although not universally accepted, that the incidence of late complications is greater after inadequate arsenical treatment. This possible danger is chiefly apparent during the early stages of the disease, when arsenic may destroy the treponemata in the skin lesions which are provoking extensive specific antibody development, and thus may diminish the latter and interfere with the host's development of specific immunity without destroying all organisms in the body. Inadequate treatment given later appears to have little. effect on accelerating complications, as by then the body has developed its own immunity which cannot be altered by any treatment. In view of these findings the theoretical danger of inadequate treatment during the incubation of the disease is a matter requiring the most careful consideration; while it is accepted that experimental syphilis in the rabbit is curable by one large dose of arsenic, no such uniform result could be expected in man as the dose required would be too toxic. Furthermore it is acknowledged that syphilis in the rabbit is a condition more readily cured than in man. Whether a single massive dose of penicillin could ever cure human syphilis is a problem that cannot be solved definitely for years to come.

\section{Syphilis d'Emblée}

Syphilis d'emblée is a term used sometimes rather freely but often imperfectly understood:; possibly, as Lane (1912) suggests, cryptogenic syphilis would be a more satisfactory name for this phenomenon. Pernet (quoted by Lane) suggested that the condition was merely syphilis in which the primary lesion was so insignificant as to escape the notice of both patient and doctor, and that therefore the condition did not in fact exist as a separate entity. Lane, however, quoted six cases of his own, in none of which was it possible to demonstrate the site of entry of the organism, and all of whom developed a virulent form of invasive syphilis which, with the limited armamentarium of therapeutic agents of those days, was exceptionally difficult to control. He also quoted two cases described by Jullien and several described by Walsch in which, although the site of entry of the organism was known, no local lesion developed at this site but a generalized infection of a secondary type of syphilis became evident at an early stage, this frequently being of a particularly virulent type. Lane, in discussing these cases, points out that the absence of the initial localized skin lesion appeared to be associated with an unusually virulent type of generalized syphilitic infection, and he endeavoured to explain this on the well known principle, particularly evident in his day of limited effective chemotherapeutic agents, that the earlier treatment was begun the more satisfactory was the prognosis and the less virulent were the subsequent stages of the disease.

It is possible that Brown and Pearce's law of inverse proportion may have been the important factor affecting the condition, namely, the absence of localized initial skin lesion, by which the immunity of the body as a whole to the invading organisms would be considerably below that found in cases with skin lesions in which specific antibodies are presumably being formed.

Boeck's work in Oslo, and Bruusgaard's subsequent observation, have already been mentioned, and in the cases that Bruusgaard (1929) managed to examine subsequently the relative absence of any severe complications of untreated syphilis is hardly in accordance with Lane's explanation.

\section{The Present Study}

In this paper an attempt is made to survey the relevant literature, to consider the theoretical possibilities, and to endeavour to correlate them with the clinical histories of the cases described here and elsewhere. 
That the use of penicillin was likely to lead to the masking or delay of the initial or primary lesions of syphilis was recognized by all venereologists as-soon as this treatment became available for general use. In 1945 Lydon and Scott Cowe emphasized this danger and suggested that gonorrhœea should be treated with $2,000,000$ to $3,000,000$ units to cure the potential syphilitic infection as well; an alternative suggestion was made by these authors that gonorrhœa treated with penicillin should be kept under observation for two years with serological tests. Other writers followed with suggestions for shorter periods of observation. It is suggested that in the present state of our knowledge it is too early to be dogmatic on this very important point ; too few cases have so far been reported to allow a sound reliable opinion to be formed.

In this paper a short series of cases which has been collected over a period of about eighteen months is presented, all but one of which have been seen and treated personally; some of these show an incubation period considerably in excess of any reported up to the present, so far in excess, indeed, that one is tempted to accept the easy explanation of a subsequently acquired syphilitic infection after the initial gonorrhœa. These patients have, however, been carefully interrogated and the significance of their statements explained, and as far as it is ever possible to be certain of a patient's history I believe these histories to be correct ; I share the view of many venereologists that patients well handled are generally very truthful, especially if they can be made to realize that such truthfulness is in no way to their disadvantage. The total number of cases from which these are selected was in the region of 6,000 ; of these, naturally not all were seen personally but case records have been examined, any relevant patients examined and questioned, and all doubtful cases discarded.

Destructive criticism of facts and records that do not accommodate themselves to an accepted view is often easy, and Cronin (1947) in his criticisms of Batchelor's and others (1946) cases, appears to fall into this error. We must recognize that new facts may come to light altering existing conceptions ; such ideas must be examined critically, and if they are substantiated some reorientation of our existing views on the subject may be required. I find it surprising that venereologists, who as a whole are noted for their critical and almost sceptical outlook, have accepted with surprising complacency, within a period of months after the introduction of penicillin treatment for gonorrhœa, the principle of a routine six months' surveillance period of patients after penicillin treatment for gonorrhœa.

\section{Animal Experiments of Magnuson and Eagle}

Some very valuable animal experimental work in this subject was carried out by Magnuson and Eagle (1945), who prepared a centrifuged emulsion of syphilitic rabbits' testicles, thus separating the treponemata, and diluted this preparation in varying proportions so that an accurately regulated inoculum could be injected. The injection was carried out intradermally at different sites in varying concentrations; they used a large number of experimental animals, which were given a single injection of penicillin, the dose employed being about 1/32nd of the estimated amount required to cure rabbit syphilis, and estimated to be equivalent to about 120,000 units in man. With a small inoculum of treponemata and penicillin given on the third day after inoculation, only 1 per cent. of the experimental animals showed lesions in which treponemata could be detected on dark-ground examination ; whereas, using the same inoculum without penicillin, 75 per cent. showed lesions in which treponemata were detected. When penicillin treatment was delayed until the tenth day after inoculation, no treponemata could be detected in the lesion for the first thirty days, but they were subsequently found there. One case was reported in which penicillin was given on the fourteenth day after inoculation with treponemata, after which a lesion in which treponemata had been seen quickly became free of live treponemata and in a few days had healed ; careful observation showed no subsequent sign of relapse. Although manifestations of syphilis . were delayed, these authors reported no cases of an asymptomatic infection after penicillin, but recorded that some lesions were insignificant and might well have been missed except on very careful examination. Summarizing their results, they stressed the importance of two factors in the suppression or delay of the primary syphilitic lesion. These were the total number of 
treponemata inoculated, and the stage at which penicillin was given; they demonstrated conclusively that the earlier the penicillin was given the greater was the likelihood of delaying or suppressing the lesion. From their findings they suggested that human syphilis might sometimes be aborted by early treatment with penicillin, and went so far as to suggest the use of penicillin prophylactically; the very serious danger of such a step, however, must be obvious in our present state of knowledge, and fortunately there is no record of this having been done clinically.

\section{Other Rabbit Experiments}

Further important experimental work with rabbits was described by Eagle, Magnuson, and Fleischman (1946), who demonstrated that a constant low concentration of penicillin in the body over a longer period was a great deal more effective in curing experimental syphilis than a massive concentration over a short period. They demonstrated that the number of injections given to an experimentally infected rabbit over a fixed period of treatment showed an inverse ratio to the total curative dose of penicillin required. By increasing the frequency of injections over that period a smaller total dose of penicillin was required to cure syphilis in the rabbit; they found that, when the number of injections was decreased, more penicillin was required during that same period to effect cure.

Comparing curative effects of penicillin and mapharside in rabbits, weight by weight, the former was ten or twenty times more effective in the rabbit, but in the human subject they estimated penicillin to be only two to four times more effective by weight.

These findings were confirmed by Carpenter and others (1946), who inoculated rabbits intratesticularly with a suspension of treponemata; six weeks later they started intramuscular penicillin treatment, and they found that the equivalent of $3,500,000$ units in man given in a single dose did not cure the condition; the same or even a smaller dosage given over 16 hours did frequently cure the disease, and if this period of treatment was extended a smaller total dosage was required. By the time they started treatment, however, a widespread dissemination of treponemata must have taken place. In both these articles the relative ease with which rabbit syphilis can be cured as compared with human syphilis was stressed.

The results reported by Cole and others (1946), already described, although not comparable with results from single massive doses or a dosage spread over a period of 24 to 48 hours, cannot lightly be disregarded, and it is obvious that the dangers of undertreatment with penicillin are very real; the effect of inadequate arsenic therapy on the activity of the treponema has already been described. These figures would suggest that penicillin has at the very least an equal effect if given in quantities insufficient to effect a complete cure ; in view of its more rapid destructive effect on the organism, it may well be that the effect of undertreatment of syphilis with penicillin is even more serious, as there is less chance for the skin to develop specific antibodies and provide the body with some immunity. When penicillin is given sufficiently early to abort all skin lesions and yet not in sufficient dosage to destroy every organism in the tissues, the body may be deprived of any chance of acquiring immunity and if any organisms are still present the whole system would lie defenceless before them when they subsequently developed and multiplied.

\section{Dual Infection}

Examination of the literature on this subject shows that less than 100 cases of dual infection have been described with full details; and as with one or two exceptions the incubation period is less than 90 days the conclusion has been drawn from these entirely negative findings that the incubation period does not in fact exceed 90 days. Accumulative evidence of a negative nature over a long period, combined with the absence of any contradictory reliable positive evidence, would suggest that such a theory might well be true, but it is considered too early in the present instance to accept this hypothesis, and although the cases quoted in this paper are few in number, I consider it to be in the best interests of veracity to try thus to check this complacent attitude.

\section{Other Literature}

Fromer and others (1946), after drawing attention to the febrile reactions sometimes seen after penicillin treatment for gonorrhœa and suggesting that these are JarischHerxheimer reactions, suggest that when 
penicillin is given during the incubation of syphilis the disease may first manifest itself as a delayed generalized cutaneous syphilis without any localized lesion at the site of entry. They advise that cases should be under observation for four months after their initial treatment for gonorrhœa with penicillin. They found that Jarisch-Herxheimer reactions develop within eight hours of the penicillin injection, and are found in 90 per cent. of such cases in which syphilis is present but not yet evident as a chancre or rash. Cole (1946) and his fellow workers' results of the treatment of syphilis with small doses of penicillin must be considered to be of great importance in spite of their rather vague definitions of the relapses. Although the relatively small number of cases described make them of limited value from the statistical point of view, this series of Cole does reveal the danger of undertreatment of syphilis with penicillin, suggesting that while the usual interval to the serious late complications is decreased, their incidence is increased. With the results shown in Cole and others' series, it is unlikely that anyone will wish to repeat this work in humans. They, like other workers, found that within 12 to 18 hours of the administration of penicillin no treponemata could be found in any of the superficial lesions.

Reports of cases relevant to the subject of this paper on the whole show a very similar picture with some delay in the diagnosis and an attenuated form of the primary and secondary stages of the disease.

Van Slyke and Steinberg (1944) describe two series of cases of gonorrhœea that had relapsed after sulphonamide treatment. These were given penicillin injections intramuscularly; in their first series, comprising 114 cases, the patients received 80,000 units over a period of twenty-four hours. In their second series, comprising 65 cases which received 125,000 units over a period of $7 \frac{1}{2}$ hours, two of the patients had penile ulcers in which no treponemata could be found the day after treatment ; three weeks later, however, both patients had positive serological tests. The authors concluded that early treatment with penicillin could mask the primary stage of syphilis entirely and recommended darkground examination of any suspicious lesions before penicillin administration, and careful observation of the patient subsequently- after describing to him the nature of any expected further manifestations.

Baier and Pincus (1944) describe one case of gonorrhœa treated with 100,000 units of penicillin two days after a tiny sore was noted on the penis. Repeated dark-ground examinations of this sore were negative after penicillin therapy, and it eventually healed fourteen days after appearing; six weeks after the penicillin treatment serological tests were strongly positive for syphilis. From this the authors concluded that penicillin might destroy or assist in destroying treponemata in the localized skin lesion.

Osmond (1945) reports a case of gonorrhœa treated by two-hourly injections of 20,000 units of penicillin, giving a total of 100,000 units. Subsequently a small ulcer developed on the shaft of the penis, but all attempts to demonstrate the presence of treponemata failed and serological tests were negative. Later this lesion healed, but further ulcers developed in which treponemata were found. This occurred on the eighty-second day after the initial exposure to infection, and serological tests at this stage were still negative.

Canizares (1944) describes one case of gonorrhœa treated with 50,000 units of penicillin. A papular lesion present on the penis at that time was examined without result for treponemata ; it then healed, but recurred ten days later, when treponemata were present. Horn and Dakin (1944) cite a case of gonorrhœa, resistant to sulphonamide treatment, which was given 5 injections of 20,000 units of penicillin in aqueous solution ; 34 days later, 52 days after exposure, a small ulcer developed in which treponemata were found.

Scott Cowe (1945) reports a patient with gonorrhœa treated with 100,000 units of penicillin who later developed a sore in which treponemata were found; the incubation period from exposure to diagnosis was 62 days.

Lydon and Scott Cowe (1945) reviewed the effect of systemic penicillin treatment of skin lesions - which has already been described in this paper-but claimed that penicillin was dangerous to use in the treatment of syphilis except in the very early stages, and then should be used only in large doses, as penicillin does not reach the cerebrospinal fluid to any extent and 50 per cent. of cases of generalized secondary syphilis do show involvement of this fluid. Subsequent findings by other workers do not 
confirm this statement, and Stökes (quoted by Willcox, 1946) considered that penicillin was effective in all types of neurosyphilis and that the most striking effect was on the cerebrospinal fluid. Lydon and Scott Cowe described two cases, one of which illustrated the usual finding of a clinical chancre which on bacteriological examination after penicillin treatment was negative. Subsequent serological tests were positive. Their second case was of gonorrhœa resistant to sulphonamide therapy. The patient had round the fraenum an indurated œdematous lesion which looked like a chancre, but bacteriological confirmation was not found. After 100,000 units of penicillin, given over ten hours, this suspicious lesion vanished and at the time of the report had not reappeared. The patient was, however, under observation. They ask the question which has not yet been satisfactorily answered, "Does incubating syphilis inadequately treated give rise to an early incidence of the normally late serious complications of syphilis?" They suggested treating all gonorrhœa cases with a dosage of about 2,500,000 units of penicillin, which they at that time considered adequate to cure syphilis ; as an alternative they proposed that all penicillin-treated cases of gonorrhœa should be kept under observation for two years.

Atcheson (1945) describes a case in which a maculopapular rash developed within fourteen days of the injection of 100,000 units of penicillin.

Lloyd Jones and others (1946a) reported a series of 617 cases of gonorrhœa treated by injections of penicillin in saline over a period of eight hours ; the total dosage was 100,000 units. All patients received serological tests at three and six months before being discharged. The authors claimed that in the ten double infections recorded syphilis was manifest within the accepted period of time. In another paper in the same year (Lloyd Jones and others, 1946b), the same authors described another series of 250 cases of gonorrhœa, of whom ten developed syphilis after similar penicillin treatment to those of the first series. In this series also they claim no delay, in the incubation period. None of their cases was observed, however, after six months, and no one is to know whether any of these patients subsequently developed a syphilitic infection. Case 1 of the series in this paper is doubtless shown in some similar records as an uncomplicated case of gonorrhœa.

Hailey (1944) reports a case of gonorrhœa treated with sulphonamide which developed a small penile sore; repeated bacteriological tests for this were negative, and 100,000 units of penicillin were given for the gonorrhœa ; 69 days after exposure the sore recurred, still devoid of treponemata, but at this stage the Kahn reaction became positive.

Cronin (1945) suggested that cases considered in this category should have two important qualifications: There should have been no further exposure to venereal infection after the development of gonorrhœa, and the history should suggest a genuine double infection. He reported 183 cases of syphilis of which ten had been genuine double infections after receiving 100,000 units of penicillin for gonorrhœa. He states that within two months all showed chancres in which treponemata were demonstrated. He also considered that this dose of penicillin did not prevent serological tests becoming positive within the normally expected period.

\section{Syphilis Obscured by Local or Systemic Penicillin}

The same author (1946) describes seven cases of great importance but not strictly relevant to the subject of this thesis ; briefly, these were all cases in which syphilis in some form was not initially recognized but the condition was treated empirically, as unfortunately occurs not uncommonly, with penicillin. One case of secondary syphilis was diagnosed as tonsillitis before the skin eruption was obvious, and when the latter did appear it was diagnosed as a sulphonamide-sensitive rash and penicillin was given instead. Once penicillin has been given in such cases, and others such as undiagnosed digital chancres, the diagnosis of syphilis may be very difficult for even the expert to prove ; penicillin cream in a like manner will destroy all treponemata in a skin or mucosal lesion for some days. The importance of the general practitioner's realizing the significance of such cases cannot be over-stressed. Cronin again (1946) reports a further series of five cases in which the diagnosis was obscured by the use of penicillin locally or systemically; he also makes three wise suggestions : serological tests should be carried out before giving penicillin for any 
condition; the whole body should be thoroughly examined at the same time for the evidence of a primary syphilitic lesion, and a temperature and pulse chart should be kept while the patient is under treatment with penicillin; the possibility of any otherwise unexplainable rise of temperature and pulse being a Jarisch-Herxheimer reaction would have to be considered. These suggestions, although excellent in theory, would present formidable difficulties, and with penicitlin now available for general use by all practitioners it is unlikely that such advice would receive universal support. The suggestion that a patient might have venereal disease has to be made very delicately, and I doubt whether every patient having penicillin would submit to such investigations or management.

Batchelor and others (1946) report seven cases of double infections after penicillin. treatment, with incubation periods varying from 39 to 184 days. It is significant that even in their short series the syphilis manifested itself in three different ways; two patients were serologically positive; three showed treponemata present in chancres, one developed characteristic secondary syphilis; and one showed a positive serological test combined with treponemata present in the primary lesion. Cronin, discussing this series, dismissed. the incubation period of 184 days as improbable because the "domestic situation" of this patient suggested that his story was unlikely to be true. From the case history in the original paper there appears to be little evidence on which to base this statement, and I have already discussed the question of veracity in venereal patients. I think that the most experienced venereologists agree that in time the truth is obtainable from most patients with venereal diseases. Batchelor and others suggest on their findings that a three months' observation period is insufficient and make a plea for sulphonamide therapy for pregnant women suffering from gonorrhœa.

Cronin (1947) reviews previously reported instances of double infections with delay in the development of syphilis and describes a further 19 cases observed by himself, with an incubation period within the usual limits of syphilis, after receiving 100,000 units of penicillin for gonorrhœa. He noted that the first clinical lesion usually developed about four to six weeks after the penicillin treatment, suggesting that the treponemata surviving the single massive dose of penicillin act as a fresh inoculum. Included in Cronin's series is one showing an incubation period of 152 days, which he apparently ignores when he claims that no cases with negative serological tests at three months subsequently became positive:

A recent personal communication from Erskine (1947) is of interest and possibly of significance: he reports that during the last twelve months he has treated four pregnant women who were found to have positive Wassermann reactions at ante-natal clinics. In each of these cases, the husband, who had been in the Armed Forces, had previously had penicillin treatment for gonorrhœa, but routine serological tests at three and six months were negative and further tests by Erskine were also negative. There was further evidence-either in the form of previous negative serological tests with former pregnancies or in the history of previous normal pregnancies resulting in healthy babies - to show that the women had not been infected previously. In none of these cases was there anything to suggest an alternative source- of infection other than the husband. Such findings, although proving little, are not easily explained and give much food for thought. The possibility of these men having acquired syphilis at the same time as gonorrhœa, the former being modified or masked by penicillin treatment, cannot be dismissed lightly. The mode of transmission of such an infection to the wives is, however, difficult to explain other than by infection from the husbands' semen, in view of the destructive effect of penicillin on treponemata in all superficial lesions ; the fact that the wives did not contract gonorrhœa suggests that conception could not have occurred before penicillin treatment for their husbands' gonorrhœa.

\section{Case Comments and Histories}

The cases listed in the accompanying table are drawn with one exception from cases seen personally at Guy's Hospital Venereal Diseases Department ; in addition, records from other venereal diseases clinics have been studied and cases described may be considered to represent a selected series out of a total of over 6,000 cases. Some of the records examined showed, however, a high defaulter rate within the first weeks after clinical cure of gonorrhœa. 
Case 1.-This patient was a married man aged 27, who on March 1, 1945, was treated in the Army with 200,000 units of penicillin for acute gonorrhœa. The incubation period of this gonorrhœa is unfortunately not known exactly, but penicillin was administered on the second day after the urethral discharge was seen. The patient responded satisfactorily to treatment, and serological tests for syphilis after three and six months were negative. Almost exactly eleven months after his penicillin treatment he attended at Guy's Hospital and asked for final tests of cure as his wife was pregnant. He stated then and subsequently that he had had no further exposure to infection other than his wife, in whom all tests were negative. Strongly positive Wassermann and Kahn tests were found which were repeated and confirmed. He gave no history suggestive of any skin or other manifestation of the disease. When put on routine anti-syphilitic treatment he showed a mild Herxheimer reaction after his first injection.

Case 2.-This patient was a single man aged 24 ; he was not seen personally, and unfortunately no serological tests had been carried out after his treatment for gonorrhœa. On Feb. 6, 1947, he was treated for acute gonorrhœa with five injections of 40,000 units of penicillin at two-hourly intervals. He was clinically cured within three days; the incubation period of his gonorrhœa was fourteen days, and he reported for treatment on the fourth day of the disease. On May 3, 1947, he reported to his own doctor with two small " pimples " on his prepuce, which were treated by the latter with penicillin cream. Two days later he reported at a clinic and was found to have œdema and induration behind the coronal sulcus associated with enlarged inguinal glands. He also had a faint papulomacular syphilitic rash. Dark-ground examination of the penile lesion revealed no treponemata, but a strongly positive Wassermann reaction was discovered.

Case 3.-This patient was a single man aged 34. On Oct. 2, 1944, he reported at Guy's Hospital clinic and was found to be suffering from gonococcal urethritis after exposure to infection six days before. He was treated with sulphonamides, which cleared up his discharge, but he relapsed ten days later. On Oct. 12, 1944, he was admitted to hospital and given a total of 130,000 units of penicillin in the form of five two-hourly injections. Within four days he showed clinical cure, which was confirmed by negative serological tests after three and six months. On Oct. 16, 1945, he reported with two small "pimples" on his penis which had been present for one week. He was certain that he had had no further exposure to infection since the previous attack of gonorrhœa. Dark-ground examination of these pimples was negative, as were the serological reactions. On Oct. 31, 1945, penile sores were healed but the Kahn test was weakly positive. On Nov. 7, 1945, he had developed a maculo-papular eruption on the trunk-which did not irritate-and some enlarged lymphatic glands; Wassermann and Kahn reactions were strongly positive. Two days later he developed a Jarisch-Herxheimer reaction after the first injections of penicillin and neoarsphenamine.

Case 4.-This patient was a single man aged 27. On July 26, 1947, the patient reported on the first day of urethral discharge, which appeared six days after exposure to infection. He received 250,000 units of penicillin in oil, in one injection. On Sept. 16 and Nov. 25, 1946, serological tests were negative. On March 13, 1947, he reported with a penile sore which had been present for four days. Dark-ground examination revealed the presence of Treponemata pallidum. Serological tests were negative.

Case 5.-The patient was a single man aged 23 . In September, 1946, he was treated at Glasgow for acute gonorrhœa, being given 200,000 units of penicillin in five two-hourly injections. Clinically he was rapidly cured and he defaulted without any further tests. On Feb. 18, 1947, he was seen with a large.indolent sore in the suprapubic area which had been present for two weeks. He assured us that he had had no further exposure to venereal infection since September, 1946. Treponemata were found in the lesion, and his blood showed strongly positive Wassermann and Kahn reactions. He developed a Herxheimer reaction after his first neoarsphenamine injection.

Case 6. - This patient was a married man aged 22. On Nov. 23, 1946, he reported with acute gonorrhœa which had been present for two days. He had exposed himself to infection nine days previously. He was treated with 250,000 units of penicillin in oil in one injection. Unfortunately he failed to report for tests after clinical cure. On March 31, 1947, he reported with multiple erosions of the penis and signs on the skin and in the mouth of early secondary syphilis. He admitted exposure to infection one week previous to attending but otherwise none since his previous attendance. Wassermann and Kahn tests were strongly positive, and treponemata were found to be present in the lesions.

Case 7.-This patient was a single man aged 33 . On May 14, 1946, he reported with acute gonorrhœa after exposing himself to infection five days earlier ; he was treated with 200,000 units of penicillin in a single injection. His Wassermann reaction was negative. On June 25, 1946, routine Kahn tests 
were weakly positive. He failed to attend again before Sept. 3, 1946, owing to a misunderstanding. Wassermann and Kahn reactions were then strongly positive. Careful examination of this patient failed to reveal any signs of syphilis, and there was no history to suggest skin manifestations of the disease.

Case 8. - This patient was a single man aged 22. On Jan. 1, 1946, he reported with gonorrhœa contracted after exposure to infection seven days earlier. He was treated with 200,000 units of penicillin in oil in a single injection. On Jan. 10, serological tests were negative. On Feb. 28 he reported with a small ulcer on the meatus of the urethra. Dark-ground examination revealed the presence of Treponema paltidum. Serological tests were negative.

Case 9.-This patient was a single man aged 40 . On April 8, 1947, he reported with acute gonorrhœa after exposure to infection seven days previously. He was treated with a single injection of 125,000 units of penicillin in oil and sulphathiazole $1.5 \mathrm{~g}$. every eight hours for four days. By April 13 the gonorrhœa was clinically cured, and by April 25 serological tests were negative. On May 8, 1947, he reported with minute nodules on the penis which, although clinically quite unlike a chancre, revealed Treponemata pallidum on dark-ground examination.

Case 10.-This patient was a single man aged 29.

TABLE

INCUBATION PERIOD AND METHOD OF MANIFESTATION OF SYPHILIS IN SELECTED PERSONALLY OBSERVED CASES

\begin{tabular}{|c|c|c|c|c|c|c|c|}
\hline \multirow[b]{2}{*}{$\begin{array}{l}\text { Case } \\
\text { No. }\end{array}$} & \multicolumn{2}{|c|}{ Time in days } & \multirow[b]{2}{*}{$\begin{array}{l}\text { Dosage of } \\
\text { penicillin } \\
\text { in units }\end{array}$} & \multirow[b]{2}{*}{$\begin{array}{l}\text { Result } \\
\text { of Kahn } \\
\text { test }\end{array}$} & \multirow[b]{2}{*}{$\begin{array}{l}\text { Result of } \\
\text { Wasser- } \\
\text { mann } \\
\text { test }\end{array}$} & \multirow[b]{2}{*}{$\begin{array}{l}\text { Result } \\
\text { of dark- } \\
\text { ground } \\
\text { examina- } \\
\text { tion }\end{array}$} & \multirow[b]{2}{*}{ Clinical notes } \\
\hline & $\begin{array}{l}\text { from } \\
\text { date of } \\
\text { exposure, } \\
\text { to treat- } \\
\text { ment with } \\
\text { penicillin }\end{array}$ & $\begin{array}{l}\text { from } \\
\text { date of } \\
\text { exposure, } \\
\text { to diag- } \\
\text { nosis of } \\
\text { syphilis }\end{array}$ & & & & & \\
\hline 1 & $?$ & c. 350 & 200,000 & $+++t$ & ++ & Nil & $\begin{array}{l}\text { No physical signs of } \\
\text { syphilis }\end{array}$ \\
\hline 2 & 18 & 105 & 200,000 & Nil & ++ & Negative & Early secondary syphilis \\
\hline 3 & 16 & c. 390 & 130,000 & $\stackrel{++}{++}$ & $\begin{array}{l}\text { Nil } \\
++\end{array}$ & Negative & Early secondary syphilis \\
\hline 4 & 6 & 239 & 250,000 & Nil & Nil & $\begin{array}{l}\text { T. pall. } \\
\text { present }\end{array}$ & $\begin{array}{l}\text { Presented on first attend- } \\
\text { ance with ulcer of penis }\end{array}$ \\
\hline 5 & $?$ & c. 150 & 200,000 & $++t$ & ++ & $\begin{array}{l}\text { T. pall. } \\
\text { present }\end{array}$ & Early secondary syphilis \\
\hline 6 & 9 & 123 & 200,000 & $++t+$ & $+t$ & $\begin{array}{l}\text { T. pall. } \\
\text { present }\end{array}$ & Early secondary syphilis \\
\hline 7 & 5 & 46 & 200,000 & $\begin{array}{l}++ \\
+++\end{array}$ & $+t+$ & Nil & $\begin{array}{l}\text { Latent syphilis - symp- } \\
\text { tomless }\end{array}$ \\
\hline 8 & 7 & 66 & 200,000 & Negative & Negative & $\begin{array}{l}\text { T. pall. } \\
\text { present }\end{array}$ & Urethral chancre \\
\hline 9 & 4 & 32 & 125,000 & Negative & Negative & $\begin{array}{l}\text { T. pall. } \\
\text { present }\end{array}$ & $\begin{array}{l}\text { No delay in development } \\
\text { of chancre after peni- } \\
\text { cillin and sulphonamides }\end{array}$ \\
\hline 10 & 35 & 45 & 250,000 & Negative & Negative & $\begin{array}{l}\text { T. pall. } \\
\text { present }\end{array}$ & $\begin{array}{l}\text { Sore on glans penis pre- } \\
\text { sent at first, disappeared } \\
\text { after treatment and } \\
\text { later recurring }\end{array}$ \\
\hline
\end{tabular}


On Oct. 3, 1946, he reported with gonorrhœa which had been present for ten days and which had developed after a 25-day incubation period. He was treated with 250,000 units of penicillin in a single injection. The next day he developed a small superficial sore on his glans penis associated with enlarged inguinal glands. Repeated examinations for treponemata were negative, as were serological tests. By Oct. 9 the lesions had healed, but on Oct. 13 there was recurrence of a sore in the same situation; dark-ground examination revealed treponemata. Wassermann and Kahn reactions were negative.

These cases present some unusual features which strongly suggest that three or six months' surveillance for syphilis is too short a period after the penicillin treatment of gonorrhœa. In some of the cases also the signs of syphilis are slight or even absent, and there may be little or nothing to induce a defaulter to return for advice after the clinical cure of gonorrhœa. An obvious criticism and method of explanation is that the patient's history is unreliable. Many will say that the average venereal patient is unlikely to tell the truth, but, except for the proportion found in any group to whom truth is anathema, I think the correct story usually comes out in the end in a happy and wellrun clinic. The cases reported here were reliable men to whom the importance of their story was explained, and there appears to be no reason to doubt that their stories were substantially correct.

Case 1 is possibly an example of the most dangerous type of all, the symptomless development of syphilis in which the progress to late and serious complications may be accelerated by inadequate therapy. Case 2 is included although I never had the opportunity of interviewing him and verifying his story. The extremely long incubation period of Case 3 is surprising in that penicillin in a small dosage was given at a relatively late stage of the gonorrhœa. This patient, however, appeared to be a most reliable witness. Case 5 was an unsatisfactory patient in that he ignored tests for cure; he was, however, quite emphatic about the absence of further exposure and appeared to be only too willing to make up for his lapse in defaulting without tests. In Case 6, the only intervening exposure could obviously have had no influence on the development of the secondary eruption. Case 7 is interesting in that, like Case 1, syphilis could only be diagnosed on serological tests ; all cutaneous manifestations of syphilis appeared to have been suppressed. In a similar manner the primary lesion in Case 9 was clinically quite unlike a chancre, and the ordinary patient and many practitioners would almost certainly have ignored this lesion, and yet dark-ground examination showed a large number of treponemata present. Case 10 illustrates a phenomenon noted by many previous workers, namely, the appearance and healing of early lesions without any sign of treponemata being present and the subsequent reappearance of the lesion with treponemata demonstrable.

\section{Statistics of Double Infection}

The true double infection of syphilis and gonorrhœa-and in that group only those cases in which the two diseases appear to have been contracted simultaneously are includedhas always been a subject of interest to the venereologist because of its surprising rarity. Kemp and Shaw (1936), describing 500 cases of gonorrhœa in males, found that 1.4 per cent. subsequently developed syphilis in addition. More recently Lloyd Jones and others (1946b) recorded a series of 250 cases of gonorrhœa of which 4 per cent. had double infections, in another series the same authors (1946) record 617 instances of gonorrhœa of which 1.6 per cent. became double infections. In both these series of cases syphilis appeared after the penicillin treatment of the gonorrhœa. In a recent series, collected personally at a well known London venereal diseases clinic, of 257 cases of gonorrhœa treated with sulphonamides 2.8 per cent. were double infections ; of the total number, however, just under 10 per cent. defaulted after clinical cure of gonorrhœa and before syphilis could be expected to develop.

The statistical reports of the Guy's Hospital Venereal Diseases Department from 1939 to 1947 have been examined, and the period divided into the pre-penicillin and postpenicillin eras. Before penicillin treatment was started, 1,376 gonorrhœa cases were seen, of whom 1.3 per cent. had double infections; after penicillin was first used 701 cases of gonorrhœa are recorded, of which 0.9 per cent. had double infections. From such figures little reliable information can be drawn; a fair comment would be that the percentage of double infections has fallen slightly in a relatively small series at a time when the general increase in the incidence of syphilis might lead one to expect a rise in this figure. It might be argued that penicillin has some effect in suppressing some of the potential syphilis infections, but it would be unwise to assume this until a considerably larger number had been collected and compared. Records were 
studied in other clinics, but unfortunately from reading case records it was not possible in most cases to collect reliable figures as notes did not appear to have been kept with this possibility in mind, and the figures obtained, which varied considerably, were discarded as misleading.

An interesting observation was made in a seamen's hospital clinic in which patients had contracted their infections in places where syphilis is as a rule particularly rife; Out of 300 case records only one double infection was found. It was interesting to note that all had had penicillin, frequently in rather larger doses than is customary-presumably an attempt to guard against relapse at sea while away from medical supervision.

It is unfortunate that venereology, a branch of medicine in which records and statistics have always been regarded as of the greatest importance, has neglected double infections in its statistics. It is only since the advent of penicillin that the significance of this incidence has been appreciated, and yet even in the records compiled in the official venereal records of the United States of America, a country in which statistics have always been accorded their due importance, while syphilis is subdivided into four groups, there is still no statistical record of double infections in 1946. It is obvious that a considerable relative decrease of double infections in the absence of any sudden fall in syphilis rate would at least suggest that for some reason some double.infections were being masked or suppressed, especially if the same drop was not noted in sulphonamide-treated cases of gonorrhœa. To decide this point one way or the other, an almost nation-wide collection of cases would be required to obtain sufficient numbers to eliminate errors found in smaller series.

It appears from the literature on the subject that there cannot be the slightest doubt that penicillin administered during the incubation period of syphilis, as occurs in the treatment of gonorrhœea, can delay the development of the former disease and may in many ways mask its usual presenting features. Unfortunately there has been no uniformity in the way in which the disease has manifested itself; an analysis of $\mathbf{4 0}$ cases reported with details in the literature shows that 22 were diagnosed by demonstration of Treponema pallidum in a superficial lesion, 13 were found to have positive serological tests only, and 5 presented as generalized secondary syphilis. A similar lack of uniformity is seen in the cases described in this paper. It has been shown that it is as a rule impossible to demonstrate treponemata in lesions of the skin or mucous membrane within a few hours of systemic penicillin treatment, and, as might be expected, a large number of the cases described presented with lesions clinically suggestive of primary chancres in which, however, no organisms could be demonstrated. After a short period these lesions healed, but subsequently these either recurred and treponemata were usually found in the recurrent lesion, or there was no further localized lesion but the patient developed all the signs and symptoms of secondary syphilis ; in some cases, however, the diagnosis was made on a positive serological test only, without any accompanying signs or symptoms.

If the ultimate development of syphilis is obvious enough to make the patient seek further advice, no very great harm may have been done, but it is alarming to note, after inspecting some 6,000 case records, the large number of defaulters after rapid clinical cure of gonorrhœa with penicillin. The venereal habitué now finds that gonorrhœa is cured more rapidly and satisfactorily than a common cold, and, with this realization, virtue loses yet another inducement and promiscuity becomes more rife; penicillin soon restores him to his usual health and he readily forgets the warning he has received about routine tests at three and six months intervals. The manifestation of secondary syphilis, when modified by previous penicillin treatment, may also be trivial and transient and escape the notice of an unobservant patient or even his medical practitioner.

The few cases quoted in this paper are valuable in that they provide highly suggestive evidence that the Treponema pallidum is behaving under the influence of penicillin in a way not yet fully understood. The evidence given of the fall in incidence of double infections at a time when syphilis has been on the increase for a few years is significant but not conclusive with such a small series. However. after discussing this incidence with venereologists over the last few months I am left with the impression that all, without exception, have been surprised at what appears. in their 
opinion, to be an unexpected fall in this incidence over the last three years.

Possibly in those cases failing to develop a primary lesion or even secondary generalized signs, we may be seeing an artificial syphilis d'emblée. Morgan's experiments with rabbits in which he showed that the inoculation of less than 30,000 treponemata produced no local lesion but did in due course cause a systemic syphilitic infection, as was shown by positive serological tests, suggest that this is a possibility. The effect of penicillin may in some cases attenuate the original inoculum to such an extent as to interfere with the local growth of treponemata. It is known, however, that treponemata in the skin are more vulnerable to treatment than those that are disseminated and lie sheltering in some lymph node. The similarity between this hypothetical case and Morgan's experimental rabbit is obvious.

The importance of the skin as an organ of immunity has always been recognized in syphilis. Urbach (1946) in his book on allergy points out that in fevers and diseases like syphilis and tuberculosis, where the skin reactions are severe, visceral manifestations are less marked. Brown and Pearce (1921) formulated their law of inverse proportion on similar findings.

Bloch (1923) (quoted by Urbach) managed to transfer specific hypersensitivity in Thiersch grafts, demonstrating the existence of antibodies in the epidermis. Haxthausen (1939) (quoted by Urbach) showed that intracutaneous injections of foreign serum produce a greater reaction in the skin than intravenous injections, suggesting that the bulk of the effective cutaneous antibodies are formed in the skin itself, Matsumoto (1936) (quoted by Urbach) demonstrated the greater effect of giving vaccines intradermally, a fact of great importance to all dermatologists. All these findings suggest that a brisk primary or secondary reaction in-syphilis is, from the ultimate prognostic point of view, an excellent sign. Yet there is evidence available already that we are suppressing or modifying this reaction with penicillin given during the development of the disease. Even provided all such cases are ultimately correctly diagnosed and treated, there must be some doubt in our minds as to whether their ultimate prognosis is as good as that of cases of uncomplicated chancres treated in the orthodox manner.

\section{The Skin and Immunity}

At the 1947 Annual Conference of the British Association of Dermatology and Syphilology at Leeds, the main discussion was on the effect of calciferol on tuberculous disease of the skin. Results reported over a relatively short period of time give a very encouraging picture for the future of the patient suffering from lupus vulgaris. Several workers were, however, distinctly disturbed to note that in some cases, as the skin condition was improving, tuberculous lesions developed or flared up in the lungs. Although no statistics were available the impression formed was that such a complication was becoming not uncommon and was certainly a great deal commoner than previously when lupus, although sometimes controlled, could not be cured. An analogy was drawn at this meeting between this phenomenon and syphilis with special reference to Bruusgaard's findings, showing the great rarity of tertiary skin lesions combined with neurosyphilis. Lane's cases of syphilis d'emblée described in this paper furthermore suggest that a large well developed chancre may be a good prognostic sign.

Stokes and others (1934) in their survey of the results of treated syphilis compared their figures with Bruusgaard's findings in Boeck's cases. The most striking difference is in their relative late skin, mucosal, and bone infection figures; in the 3 to 10 year group Stokes reported 1.2 per cent. in this form, while Bruusgaard reported 31.7 per cent. and yet the latter's final figures for general paralysis of the insane in untreated cases was estimated finglly at 0.6 per cent. That the skin has some influence on immunity is suggested by these figures alone. The exact form of this immunity is not known, and the question has been discussed in this paper. The passing of the primary and secondary stage of syphilis is heralded by massive destruction of treponemata in the superficial lesions. Exactly how this comes about is again unfortunately not known, but it is known from clinical experience that the skin and mucous membrane are the only organs of the body, with the possible exception of bone, liver; and the eye, in which spontaneous healing of a syphilitic lesion normally takes place. It therefore would appear to be the height of folly to deprive this organ of its chance of producing some immunity against the disease, unless the most rigorous treatment 
is subsequently to be given to eradicate the treponema from the body.

\section{Eliminating Risk of Masked or Modified Syphilis}

In view of the cases described in this paper and the previously recorded facts and hypotheses, it would appear that the case for dissociating penicillin from any risk of masking or modifying syphilis, even after the six-month period of surveillance that is now generally accepted, is not proven. In spite of the relative rarity of double infections, the very serious potential results of an undetected masked syphilis necessitate a careful examination of this subject ; it is too early yet to assume confidently that all such cases showing no signs of syphilis are entirely free from infection. Chesney's account, already described earlier in this paper, of experimentally infected rabbits and monkeys in whom treponemata, capable of reinfecting another animal, were found in lymph nodes without any other signs of syphilis, even in the form of a positive serological test, must be remembered.

Certain suggestions therefore are made with a view to eliminating this risk as far as possible.

1. Bigger (1944) showed that, in vitro, penicillin and sulphathiazole showed a synergic reaction, having an enhanced combined effect on Streptococcus hamolyticus and Staphylococcus aureus. It is suggested, therefore, that a combined therapeutic course of penicillin and sulphathiazole be given, so that the dose of the former may be dropped to 125,000 units ; this routine has been in use at Guy's Hospital clinic for some months and has proved very satisfactory. One case of double infection in which the gonorrhœa was treated in this manner is quoted in my series as showing no delay in the development of syphilis. Cronin, whose work has already been described, claims that with 100,000 units of penicillin there is little or no delay in the development of syphilis. My figures and those of published cases suggest, as might be expected, that doses of 200,000 units and more have an appreciable delaying or masking effect.

2. A patient about to receive penicillin for gonorrhœa should always have a serological test for syphilis performed before treatment ; he should also be carefully examined for any evidence of early chancres not noted by the patient.
3. Records of true double infections should be kept. Only when the percentage of this association in a very large series of cases is known is this of any value ; a substantial fall in this percentage, during the routine sixmonths period of surveillance at present generally accepted, as compared with the days before penicillin was used in treatment, would suggest that syphilis is possibly being suppressed or masked.

4. No pregnant woman should be given penicillin for gonorrhœa, except either immediately before full term or after two unsuccessful courses of sulphonamides, by which time a chancre might be expected in most cases to be visible. Batchelor (1946) originally made this suggestion and the possibility of masking congenital syphilis in the baby is, in our present state of knowledge, very likely.

5. In view of the widespread use of penicillin in present times, all practitioners should appreciate that systemic penicillin rarely gives rise to any skin eruptions, except occasionally urticaria, or rises in temperature and rigors, and they should regard the latter as potentially. a Jarisch-Herxheimer reaction and the former as possibly a generalized cutaneous form of syphilis brought on by the penicillin injection. Cronin (1946) describes five cases that might well have occurred in general practice where the practitioner, unless fully acquainted with the facts described above and their significance, would very probably have misseg the true diagnosis and dismissed an evanescent macular rash as a toxic erythema, unless previously warned of the possible complications of penicillin treatment.

6. All patients after having penicillin treatment for gonorrhœea should be warned of the dangers of not attending for further tests as instructed, or of not reporting any abnormality. While there are obvious psychological disadvantages in this, as Cronin (1947) points out, I think the average patient will appreciate the reason after explanation and may well have more confidence in his treatment.

7. Serological tests should be carried out for at least one year after penicillin treatment of gonorrhœa. Psychologically this is bad for a certain type of patient, but the wise venereologist should have little difficulty in reassuring such patients yet at the same time impressing on them the importance of attending for such tests. At the time a physical examination 
should be made, too, in case a superficial lesion has developed without affecting a serological reaction.

8. On the evidence given by Earle Moore at a recent meeting at the Royal Society of Medicine, it is considered advisable to avoid the use of penicillin " $G$ " in the treatment of gonorrhoea, because this particular form of penicillin has a more marked anti-syphilitic effect than other forms and might tend to mask the disease to a greater extent.

\section{Conclusion}

The full answer to this problem may not be written until ten or even twenty years hence. I have endeavoured to draw attention to what I consider is a future possibility : a sudden increase in the gravity of syphilis which, while being almost unnoticed in the early stages of its onset, once again becomes the fatal and destructive disease that killed, after mentally maiming, such well known figures in the past as Guy de Maupassant and many others. The best and almost the only treatment for neurosyphilis is prevention. We must avoid taking a possible backward step in our therapeutic progress in the study of venereal disease.

\section{REFERENCES}

Allan, A. W. (1946). Brit. med. J., 1, 314.

Atcheson, D. W. (1945). Amer. J. Syph., 29, 423.

Baier, G. F. III, and Pincus, J. A. (1944). Mil. Surg., 95, 359.

Batchelor, R. C. L., Donald, W. H., and Murrell, M. (1946). Brit. med. J., 2, 151.

Bigger, J. W. (1944). Lancet, 2, 142.

Boyd, G. C., Wagner, J. A., and Hewson, G. F. (1944). U.S. Naval med. Bull., 43, 1035.

Brown, W. H., and Pearce, L. (1921). J. Amer. med. Ass., 77, 1619.

_, -(1920). Arch. Derm. Syph., Chicago, $2,675$.

Bruusgaard, E. (1929). Lancet (Commentary), 1, 135.

Canizares, O. (1944). Arch. Derm. Syph., Chicago, 50, 246.

Carpenter, C. M., Boak, R. A., and Jacobs, L. M. (1946). N.Y.St.J. Med., 46, 2150.

Carpenter, C. C. (1944). U.S. Naval med. Bull., 43, 389.
Chesney, A. M., and Kemp, J. E. (1925). J. exp. Med., 41, 479.

Chesney, A. M. (1927). Medicine Monographs : Immunity in Syphilis. London. Baillière, Tindali and Cox.

Cole, H. N., Ayres, S., Barr, J. H., Genatios, T. Held, B., Murphy, W. W., Printz, D. R., and Strauch, J. (1946). Arch. Derm. Syph., Chicago, 54, 255.

Cronin, E. (1945). Brit. J. vener. Dis., 21, 135. (1946). Lancet, 2, 84.

-(1947). Brit. J. vener. Dis., 23, 15.

Dahlström, S. (1929). Lancet (Commentary), 1, 135.

Eagle, H., Magnuson, H. J., and Fleischman, R. (1946). Bull. Johns Hopk. Hosp., 79, 168.

Frankland, A. W. (1946). Brit. med. J., 2, 159.

Fromer, S., Cutler, J. C., and Levitan, S. (1946). J. vener. Dis. Inf., 27, 174.

Hailey, H. E. (1944). Arch. Derm. Syph., Chicago, 50, 269.

Heller, J. R. (1946). J. vener. Dis. Inf., 27, 225.

Horn, E. C. van, and Dakin, J. R. (1944). Ibid., 25,365 .

Kemp, J. E., Menninger, W. C. (1936). Bull. Johns Hop. Hosp., 58, 24.

- - and Shaw, C. (1936). Amer, J. Syph., 20, 56.

Lane, J. E. (1912). Lancet, 1, 1605.

Lloyd Jones, T. R., Donaldson, E. M., and Allen, S. J. (1946a). Ibid., 1, 526. Allen, S. J., and Donaldson, E. M. (1946b). Brit. med. J., 1, 567.

Lydon, F. L. (1946). Ibid., 2, 311.

and Scott Cowe, W. R. (1945). Ibid., 1, 110.

Magnuson, H. J., Eagle, H. (1945). ·Amer J. Syph., 29, 587.

Mahoney, J. F., Arnold, R. C., and Harris, A. (1943). J. vener. Dis. Inf., 24, 355.

Morgan, H. J. (1939). J. Amer. med. Ass., 112, 311.

Osmond, T. E. (1945). Brit. med. J., 1, 853.

Ricchiuti, J. F. (1944). U.S. Naval med. Bull., 43, 1031.

Romansky, M. J., and Murphy, R. J. (1945). J. Amer. med. Ass., 128, 404.

Scott Cowe, W. R. (1945). Brit. med. J., $2,133$.

Slyke, C. J. van, and Steinberg, S. (1944). J. vener. Dis. Inf., 25, 229.

Stokes, J. E., Usilton, L. J., Cole, H. N., Moore, J. E., O'Leary, P. A., Wile, U. J., Parran, T. and McMullen, J. (1934). Amer. J. med. Sci., 188, 660.

Tuft, L. (1931). J. Immunol., 21, 85.

Urbach, E., and Gottlieb, P. M., (1946). "Allergy (Allergic Skin Diseases)." Chap. 25. London. Heineman Medical Books.

Walker, A. E., and Barton, R. L. (1945). J. vener. Dis. Inf., 26, 241.

Willcox, R. R. (1946). Nature, 158, 242. 